\title{
LEGAL REPORT
}

\section{CANADA FIRST: NORTH AMERICA ADOPTS CIRCULAR ECONOMY LAWS}

With a January 1st, 2019 compliance date now passed, the Ontario Government has been active in implementing North America's first circular economy waste diversion regime ${ }^{1}$ ("Circular Economy Law"). The landmark Resource Recovery and Circular Economy Act, 2016 (the "RRCEA") 2 adopts the complementary goals of preserving / recovering more resources, diverting more materials from landfills, and reducing greenhouse gas emissions from waste.

A fourth, less overt but truly notable aim, is to create the private market conditions for the growth of a vibrant circular economy driven by innovation, with hope that the resulting infrastructure and expertise will also be exportable across Canada and to the United States.

This paper will consider (i) what was learned in the transition away from a government-coordinated Industry-Funded Organization ("IFO") model to a private sector circular economy law; (ii) the centrality played by Independent Producer Responsibility (IPR) - where brand owners and importers are directly tasked with operating an endof-life-supply chain with non-transferable liabilities; (iii) the supporting infrastructural measures deemed necessary to IPR's success; and (iv) some of the challenges and opportunities for industry in this nascent circular economy and its intended expansionist future.

\section{PART I: Learning From the IFO Model Ontario Waste Market Necessitated Diversion}

The Province of Ontario is Canada's largest by population and has a waste generation profile all-too typical in North America. In 2014, for example, approximately 11.5 million tonnes of waste were generated in the province nearly a tonne of waste per person per year ${ }^{3}$. Forty percent of this waste is generated by households with the other $60 \%$ coming from industry, commercial businesses, and institutions. Ontario municipalities are responsible for the waste generated from households and collect, process, market and dispose of 4.9 million tonnes of material each year, at a cost of $\$ 1.2$ billion Canadian dollars.

Municipalities in Ontario have some of the most sophisticated diversion programs in North America, with 95\% of Ontario households having access to curbside recycling (Blue Box) and curbside compost programs made available to $71 \%$ of households in the province. Ontario's Blue Box program for printed paper and packaging has achieved a recycling performance of $65 \%$.

While municipalities have been driven to increase recycling through programs and regulatory provisions, such progress has not happened elsewhere in the economy and, unfortunately, 3/4 of Ontario's waste has been sent to landfill for the past 10 years ${ }^{4}$.

The Ontario government recognized the diminishing waste capacity, the need for resource conservation and the missed economic and environmental opportunities. In fact, waste diversion has been made a critical piece of the province's Climate Change Action Plan ${ }^{5}$. The larger benefit, however, as the province has identified, is replacing virgin resources in the economy with recovered resources available in Ontario.

\section{What Did Ontario Previously Create?}

The predecessor to the RRCEA is Ontario's Waste Diversion Act ("WDA") ${ }^{6}$ which created Waste Diversion Ontario ("WDO") as the regulator tasked with indirectly overseeing the diversion from landfill of a number of waste streams. Included within this group were:

- waste electrical and electronic equipment including computers, screens, peripherals, and audio/visual equipment;

- municipal solid waste streams including glass, metals, printed paper and packaging, and plastics;

- municipal hazardous and special wastes, including batteries, pressurized and aerosol containers, fertilizers, herbicides, insecticides and pesticides, paints and coatings, oil bottles and filters, and antifreeze and solvents; and

- used tires, including on-road passenger and truck tires and off-the road tires.

\section{Industry-Funded Organizations}

Through the WDA, the province designated IFOs for each of the target waste streams. IFOs enlisted service providers and coordinated the waste management activities of all of waste diversion participants for each waste stream, including the producers, haulers, collectors, processors, and re-manufacturers (depending upon the waste stream). These IFOs allocated volumes, set fee structures, rated performance, and conducted auditing and performance assessments of all the regulated parties.

With the WDO and the IFOs, two intermediary bodies were, however, placed between the producers ${ }^{7}$ (namely manufacturers, first importers, and brand owners) and the end of life supply chain. This was arguably a fatal design flaw that prevented a harmonized approach between regulator and industry.

WDO was to effectively represent the provincial environmental interests regarding waste diversion targets, education, and promotion. The IFOs, in turn, were notion- 
ally a coordinating body of industry interests, staffed by industry personnel, making specific allocations of waste resources to the various waste diversion participants in order to coordinate the overall waste diversion enterprise (the "Command Diversion Framework"). From inception, IFOs had an unclear enforcement mandate under the Command Diversion Framework in spite of their centrality within it.

An equivalent of the Command Diversion Framework had not been tried on a broad province or state-wide scale previously in North America and there was clearly going to be an element of trial and error in its execution with one or more of the regulated waste streams. The problems, unfortunately, were systemic.

\section{What Went Wrong with the Command Diversion Framework?}

Participants in Ontario's waste diversion programs have a long list of complaints with both the structure and administration of the Command Diversion Framework, including:

- the failure to make waste reduction and reuse preferable to recycling - it didn't incentivize these activities distinctly from recycling, making it the near default diversion strategy;

- producers were permitted to externalize their responsibility (both financial and liability), making them disinterested parties with no inducements to innovate;

- as IFOs effectively controlled sector monopolies, service providers, and producers were locked into protocols that left little room for needed deviation;

- the producers' waste diversion fees were, too often, disconnected from the actual costs of diverting the waste;

- poor enforcement and sanction mechanisms permitted a complacent compliance culture in some areas with an unaccounted for producer segment operating outside of the Command Diversion Framework;

- below optimal diversion rates for organics;

- no effective incentives to reduce waste;

- exclusion of important streams, such as Industrial Commercial and Institutional ("IC\&I") waste; and

- (perceptions of) lack of fairness, transparency, and certainty in the manner in which the waste resources were allocated among participants, creating uncertainty in the market.

With these attendant problems visible within the first years of inception, calls for a fundamental overhaul have been made repeatedly in the past decade from all stakeholders, with the provincial government finally acceding that the Command Diversion Framework simply did not achieve its goals ${ }^{8}$ for most, if not all, of the regulated waste streams ${ }^{9}$.

\section{Dismantling the Command Diversion Framework}

On November 30th, 2016, the Province of Ontario finally passed the RRCEA which enabled the passage of transitional legislation, the Waste Diversion Transition Act, $2016^{10}$, thereby permitting the province to move away from the Command Diversion Framework. The transition from a government-managed scheme to the Circular Economy Law without the disruption or diminution of waste diversion services and activities is not going to be easy and the government's planning for the changeover includes:

- moving the government oversight of Ontario waste diversion from the WDO to the Resource Productivity and Recovery Authority (the "Authority"), with the Authority assuming more of a night watchman role;

- enabling the Ministry of the Environment and Climate Change ("MOECC") to directly change current diversion programs; and

- permitting the MOECC to request the wind-up of the IFOs, which is anticipated to be a staged and gradual process in light of the need for continuity.

In short, the WDA and its mixed legacy are near an end, while the waste industry stakeholders (both from within Ontario and elsewhere) scramble to respond to the new regime and its challenges and opportunities.

\section{PART II: Independent Producer Responsibility Enter the RRCEA}

Viewed from the vantage point of waste diversion programs across North America and elsewhere, the RRCEA combines ambitious waste diversion goals with the dynamism of a mandated but relatively unfettered diversion market. Shades of the European Union's innovation with waste diversion ${ }^{11}$ can be seen in the outcomes sought:

- a registry of all introduced products and their primary, convenience packaging ${ }^{12}$ and transportation packaging $^{13}$ (giving rise to regulated wastes) will be established;

- "cradle-to-cradle" stewardship obligations imposed upon brand holders;

- design-for-environment; and

- expanded scope of obligated parties to include those with a "commercial connection"14.

Most important is the clear divide between market participants and the Authority, which shall under the IPR model only:

- operate as a data registry for waste diversion participants (namely producers, generators, and service providers);

- engage in active compliance and enforcement independent from the industry itself (which will include inspections, compliance orders, and administrative penalties); and

- provide limited direct oversight of obligated parties, which may well include producers, municipalities, service providers, and privately-formed collectives of obligated and related service parties.

Notable in its absence is an Authority mandate over policy or waste diversion program development, which shall be assumed directly by the MOECC ${ }^{15}$. Instead, the Authority has signaled a willingness to enforce the RRCEA mandated outcomes but the means used in achieving them will remain with the market participants. 


\section{PART III: Ontario's Strategy to Support the Circular Economy Law}

In implementing the Circular Economy Law, the province has recognized that it must actively create the conditions necessary for the regime to succeed. Simply supplanting the WDO with a market-based RRCEA is understood as insufficient for a true circular economy to germinate. No fewer than 15 actions ${ }^{16}$ have been identified in its Strategy for a Waste-Free Ontario (the "Strategy"):

- Action \#1: Empower the Resource Productivity and Recovery Authority

This is responsive to the widely-held view that the WDO was lacking a sufficiently robust enforcement mandate to compel compliance. The Authority is expressly tasked with "ensuring producer compliance with regulated requirements and a fair system that discourages non-compliance and prevents free riders" 17 .

- Action \# 2: Issue policy statements to provide clear direction on the provincial interest

The province has a laundry list of lofty goals for the reorientation of the Ontario economy away from its current disposal practices. Policy statements are intended to be issued by the Minister and serve as directives to the Authority, updating and supplementing the content of the RRCEA and regulations. They could directly impact municipal decision-making and others that hold environmental approvals.

- Action \#3: Establish a registry and build data capacity to provide for evidence based decisions

The Authority is to "collect import data from producers and other parties that conduct activities related to waste reduction and resource recovery. These efforts will help the province effectively set targets and develop policies while the Authority monitors and assesses producer performance"18. If the province fully succeeds in electronically tracking the introduction and removal of waste volumes (which admittedly is easier in some regulated waste streams than others), compliance levels will no doubt improve, though there may be unintended consequences and resulting industry concern associated with this level of monitoring.

- Action \#4: Transition existing waste diversion programs smoothly to new producer responsibility framework without disruption of services

The province is highly sensitive to any disruptions in waste diversion services occasioned by the transition. The most difficult waste diversion program to transition to an IPR is Blue Box, a municipally-run waste diversion program for printed paper and packaging and based upon 50-50 shared responsibility ${ }^{19}$. This program is mandated under Ontario Regulation 101/9420 and requires every Ontario municipality with at least 5000 residents to operate a Blue Box program.

- Action \#5: Amend the 3Rs regulations to increase resource recovery across all sectors

Provincial regulations under the Environmental Protection Act (Ontario), dating from more than 20 years ago, mandated the IC\&I sector to take positive steps in the reduction of waste:

- Ont. Reg. 102/94 Waste Audits and Waste Reduction Work Plans ${ }^{21}$;

- Ont. Reg. 103/94 Industrial, Commercial and Institutional Source Separation Programs ${ }^{22}$; and

- Ont. Reg. 104/94 Packaging Audits and Packaging Reduction Work Plans ${ }^{23}$.

Together, these process-focused obligations (largely without concrete performance targets) were the original foundational support for IC\&I waste reductions goals, frequently referred to as the "3Rs Regulations"24. The province no longer views the current 3Rs Regulations as forming part of the future IC\&I waste strategy, describing them as:

no longer adequately drive waste diversion. Their requirements are limited to large establishments and only select waste materials, and require only "reasonable efforts" to send source-separated wastes for recycling or reuse ${ }^{25}$.

Proposed changes to IC\&I waste diversion will mean the substantial revision, if not wholesale replacement, of the 3Rs Regulations and are likely to include:

- concrete diversion thresholds;

- use of "new technologies" to measure performance;

- third party monitoring, certification, and audits; and - possible imposition of IPR obligations, along with selective disposal bans.

It is the disposal bans which will be viewed as the most onus of these requirements, if, for no other reason, than the sheer volume of material to be diverted.

Action \#6: Establish service provider requirements to protect the environment while promoting resource recovery

The province takes the view that IPR and the Circular Economy Law cannot succeed without a modernization of the support services, including hauling, processing, recycling, diversion, and disposal. As part of this process, the government is seeking to adopt:

- new national, international, and industry standards for diversion and disposal;

- new technical recycling standards; and

- third party monitoring, auditing, and public reporting.

Ontario's recent end-of-life vehicle environmental standards for disposal sites ${ }^{26}$, which covers depollution, waste storage, training, and record keeping, is held up as the model for diversion standards for other regulated waste streams, including diverted waste. There may well be some difficult transitions to come in the event that comparable onerous diversion processing requirements are applied more broadly to all current and impending regulated waste streams.

Action \#7: Ensure landfills are well planned and managed to minimize the need for them and reduce greenhouse gas emissions

The province estimates that more than $70 \%$ of prod- 
ucts within the Ontario marketplace are ultimately sent to landfill ${ }^{27}$. While the Strategy acknowledges that there will still be a need for some additional landfills in the province, these will be subject to stringent new approval and operating standards to protect against environmental harms, including to drinking water sources.

More notably, the province plans to develop a landfill gas recapture protocol, focused on methane, which will permit the generation of offset credits under Ontario's new greenhouse gas reduction cap-and-trade scheme, which were made operational in January $2017^{28}$. This serves as another example of the interdependence of the circular economy and climate change regulation.

Action \#8: Establish promotion and education requirements to support public participation in resource recovery The Circular Economy Law places promotion and education requirements for waste diversion upon the industry participants themselves instead of the Authority, who are now obligated under the RRCEA to "ensure consumers are getting the information they need to properly participate in resource recovery efforts"29.

It is unclear whether those requirements will be tied to waste diversion performance and exactly how such efforts will be overseen by the Authority. Clearly, there will be a role for producers and their Producer Responsibility Organizations (PROs) to coordinate on promotion and training.

- Action \#9: Designate new materials to ensure producers are fully responsible for recovering more materials from products and packaging

The 2009 Canadian Council of Ministers of the Environment Extended Producer Responsibility Plan ${ }^{30}$ included a phased plan for the long-term expansion of waste diversion programs to a number of other products and packaging sources. The Circular Economy Law focuses on three of these sources:

- printed paper and packaging;

- food and organic wastes; and

- construction and demolition materials.

Other waste streams will be resource recovered based upon a host of considerations including:

- viability of end-of-life markets for the diverted waste;

- infrastructure capacity;

- effectiveness of existing non-regulated efforts;

- experience of diversion of such waste streams outside of Ontario; and

- harmonization with existing international efforts.

It is anticipated that the first phase of additional materials to be subject to circular economy obligations, under the RRCEA, will include:

- appliances;

- electrical tools;

- batteries;

- fluorescent bulbs and tubes;

- mattresses;

- carpets;

- clothing and other textiles; and
- furniture and other "bulky" items.

It is hoped that the diversion of existing regulated materials, along with others identified through this review and assessment process, will harmonize Ontario's efforts with those of the international community, thereby further opening the door to the collective wisdom of the broader waste diversion industry, including the European Union's Action Plan for the Circular Economy ${ }^{31}$.

- Action \#10: Implement an action plan to reduce the volume of food and organic waste going to landfill

Organics bans have yet to be broadly implemented across Canada. Ontario is considering an ambitious province-wide ban on organics which will clearly need to involve municipalities (as the current collector and disposer of household organics) in any such phased in plan. Commercial organic waste generators will need to seek market solutions to their impending diversion obligations.

- Action \#11: Implement an Excess Soil Management Policy Framework to increase the reuse of excess soil, while protecting human health and the environment

The goal of excess soil management is to redeploy excavated soils wherever possible in place of the traditional practices of landfilling such soils as wastes regardless of their current or treatable quality. This can only be done through ensuring that generators of excess soil are implementing proper testing standards which will mitigate environmental risk and managing those soils consistent with any environmental restrictions.

- Action \#12: Adopt and implement modern regulatory approaches to build on an promote innovative best practices

A critical element in Ontario's plan will be a fundamental reconsideration of what constitutes a "waste" so that industry in Ontario can fulfill the fourth Circular Economy Law goal - namely exportable innovation for the use of recovered resources for secondary and tertiary purposes. Notably, the Minister is to develop a:

risk-based approach for compliance and enforcement will also simplify legal requirements and business processes for activities which are lower-risk, less complex or have standard requirements, while continuing to protect the environment and human health ${ }^{32}$.

In short, Ontario is seeking to revisit traditional waste sector presumptions that material no longer fit for its original use is necessarily a waste to be destined for landfilling. The impediments to innovation posed by the current MOECC waste regulation and practice cannot be overestimated.

- Action \#13: Improve and establish environmental standards to provide for a level playing field and a strong foundation for markets

The province is considering the adoption of a series of environmental standards for recovered materials to 
ensure the consistency of feedstock for nascent secondary markets for diverted materials. Standards may include regulatory requirements, guidelines, best practices, and certification programs. The need for robust markets for the diverted materials, fostered by clear standards, is also central to the Strategy.

- Action \#14: Use green procurement practices to build market demand for recovered materials

Government procurement is to support the circular economy with its preference (in some circumstances) for recovered resources and recycled content, as well as more environmentally-responsible service providers.

Action \#15: Implement disposal bans to direct materials to end-markets

Perhaps the most challenging of all circular economy measures coincident with the Circular Economy Law are the proposed disposal bans set for:

- organics;

- existing diverted wastes;

- beverage containers;

- corrugated cardboard and some paper materials; and

- fluorescent bulbs and tubes.

Producers may well have allied interests in seeing that disposal bans can be used to facilitate the diversion markets.

\section{PART IV: From EPR to Circular Economy - Plastics in Canada}

The CCME (Canadian Council of Ministers of the Environment)'s Strategy on Zero Plastic Waste, dated November 2018, outlines the commitment of all provincial and territorial ministers of the environment in Canada on plastics waste. The Strategy overtly builds upon various previous multi-lateral initiatives on plastic waste reduction, many of which Canada was only tangentially involved. What is truly new and groundbreaking is the first trilateral federal, provincial, and territorial legislative commitment to a circular economy.

The CCME's last country-wide commitment on product waste was in 2009, with its Canada-wide Action Plan on Extended Producer Responsibility, which largely called for the first forms of targeted waste diversion for a number of target hazardous waste streams. The producers (i.e. product makers, importers, and/or retailers) were tasked to hold some responsibility (financial or otherwise) for such product waste and the move to cross-country, government-sanctioned waste diversion programs accelerated thereafter.

Nine years following its EPR plan, all of the environmental ministers in Canada have wholeheartedly jumped to a commitment to circular economy (on plastics), when it was Ontario alone which had formally committed and legislated these mandates up until now. The Strategy, in fact, goes so far as to call for the involvement of all supply and reverse supply chain parties (a la the Ellen MacArthur Foundation's Global Plastics Commitment) in adopting a systems approach to plastics.

\section{Provincial / Territorial Implementation}

The Strategy mandates the adoption of enabling circular economy laws for plastics across Canada, much like the 2009 Action Plan called for, and gave rise to waste diversion laws:

The implementation of this strategy will be done within the jurisdictional authority of each order of government and a future action plan will identify complementary measures between governments.

Further, the Strategy calls for the harmonization of standards and practices across all provinces and territories, in part, to reduce the regulatory burden on business. These are the same calls that have over time gradually pushed provincial and territorial waste diversion laws towards increased consistency within Canada.

\section{PART V: From EPR to Circular Economy - EEE and Batteries in Canada}

As the pace quickens in imposing full Extended Producer Responsibility for numerous regulated products and materials under Ontario's Resource Recovery and Circular Economy Act, 2016, the first design-for-environment ("DfE") regulatory standards have been introduced, and e-waste (along with lighting and batteries) will be the test case.

DfE has long featured as an aspirational goal of the European Union circular economy program, but it's been commonly out of reach of institutional product stewardship programs unable to provide incentives for individual producer innovation (see: "Extended Producer Responsibility Models For Delivering Design For The Environment." Jonathan Cocker. Lawtext Publishing. Environmental Liability - Law, Policy and Practice, Issue 6, Volume 24).

This has finally changed under the Resource Recovery and Circular Economy Act, 2016, which mandates DfE as a "provincial interest". Its Electrical and Electronic Equipment Regulation, currently in draft form but with committed compliance dates in 2020 (the "EEE Reg"), is almost certainly North America's first set of DfE regulated standards within a circular economy law.

\section{Electronics Industry Challenged Under EEE Reg}

Under the EEE Reg, brand owners and first importers of electrical and electronic equipment (EEE) are obligated to resource recovery the product content for all EEE "marketed" in Ontario for 14 separate categories of informational technology, telecommunications and audio visual equipment (everything from printers to drones).

The EEE Reg sets accelerating rates of resource recovery (or "management") obligations based upon the weight of the EEE marketed (under a prior year experience formula) as follows:

\begin{tabular}{c|c}
\hline July $2020-$ December 2021 & $57 \%$ recovery rate \\
\hline 2022 & $75 \%$ \\
\hline 2023 & $80 \%$ \\
\hline
\end{tabular}

While these recovery rates are below current practice under the outgoing government-sanctioned product stewardship scheme, there is some expansion in the product 
categories caught and there will be a transitional period of adjustment as producers determine how they will individually, or in combination with other like-minded producers, meet their obligations.

\section{EEE Management Obligations}

Under an EEE Guideline, which is likely to be a version of the international $\mathrm{R} 2$ recycling standard, the principal activities are either:

1. Refurbishment; or

2. Processing for supply for new products and/or packaging.

There is also a very limited ability to count processed glass used as aggregate. Whether any electrical and electronic equipment can be recovered by an EEE producer as compliance under the EEE Reg. isn't clear. In other words, can a company sell thousands of headphones and recycle a few speakers to satisfy its obligations? Clarity is needed.

\section{DfE Reduces Management Obligations}

Regardless of how those EEE management obligations are allocated, the real innovation lies in the DfE provisions. There are three types of DfE activities which would qualify as reducing a producer's EEE management obligations, which are capped at $50 \%$ of a producer's overall obligation. Each has been proposed as DfE policy but not in North American regulation (and arguably not legislatively in as comprehensive a package anywhere else, including in EU countries):

\section{a) Post-Consumer Recycled Glass or Plastic Content}

A producer's resulting EEE management obligation will be reduced where its product contains post-consumer recycled glass or recycled plastic content (including, it would appear, recycled content originating from outside of the province.) The consequent reduction in management obligation is reduced by the equivalent amount of the weight of the recycled content. This provision may well align with the push for recycled plastics content standards across numerous categories of plastic-containing products.

b) Extended Warranties

Where the EEE marketed in the province contains a 1-3 year warranty or a warranty of at least 3 years, the management obligation is reduced respectively by $5 \%$ and $10 \%$. There is no guidance at present as to what the scope or base terms of a qualifying warranty might look like, but clearly there is a push to incent longer lasting products. There might also be a role to be played by third party retailers who commonly offer extended warranties on a range of producers' goods.

c) Right-to-Repair

Finally, the EEE Reg. seeks to encourage right-to-repair with an obligation reduction equal to 10 percent of the weight of the EEE marketed in Ontario for products which include both no-cost information on repair (in some medium) and no or cost-recovery only charges for tools and parts to repair the EEE. The logistics and risk management issues associated with the tools and parts supply elements of this scheme may be complicated for some EEE and require more development over time. There is no doubt, however, that right-to-repair is emerging as a product standard.

Most across the electronic and electrical equipment product industries caught by the EEE Reg. will recognize these DfE provisions as works-in-progress at best. Regulated producers should also, however, recognize them as opportunities to finally gain financially for the types of environmentally-beneficial product innovations that have too long laid dormant for want of exactly these types of incentives.

\section{PART VI: CHALLENGES AND OPPORTUNITIES Will the Circular Economy Law Succeed?}

In a vacuum, the introduction of the Circular Economy Law into a "greenfield" municipal-based waste disposal regime would be challenging, given the lack of industry experience, including processing capacity. Given the (sometimes bitter) experience of the past decade under the Command Diversion Framework, however, there is substantial working knowledge of diversion of the existing regulated waste streams which, when supplemented by the collective resource recovery expertise from outside the province, may well be enough to make it viable in Ontario and then beyond. There is certainly a view that some producers will move slowly away from current IFO-based historical groupings.

\section{Used Tires as IPR Test Case}

As a first regulated waste stream under the RRCEA, used tires are viewed by many inside Canada and elsewhere as the test case for IPR. To implement, the Ontario government has introduced a draft Tire Regulation under RRCEA $^{33}$. While it remains in draft at of the time of writing, it clearly reaffirms the intention by the MOECC to let private industry decide how to establish and operate an end-of-life supply chain for used tires. Further, the draft Tire Regulation does not propose specific quotas and scoring for the end recovery uses of such tires. This may well engender the type of innovation and industry which can be exported for used tire recovery operations elsewhere.

Many uncertainties remain, however, including the most fundamental quandary facing producers - how can they comply in diverting a waste stream that they don't control and their PROs can't command?

Further, like all resources, there will be more and less preferred sources, with differential costing based upon location, resource collection efficiencies, certainties of supply, etc. There is already concern among producers of various regulated waste streams that the prime diversion sources need to be secured far in advance of the anticipated Circular Economy Law compliance date.

Finally, the Strategy, in some sectors, seems to require an economy of scale that effectively pushes segments of producers into PROs, but this may create an unintended complications under Canada's Competition 
$\mathrm{Act}^{34}$, which contains prohibitions on oligopolies and other restrains of trade. In other words, if some producers act jointly with due diligence and seek to secure the diversion supply they need to offset their product waste, their actions may be punishable by Industry Canada where the resulting $\mathrm{PROs}$ are viewed as engaging in anti-competitive activities.

\section{Could Ontario Become the Circular Economy Model for North America?}

Every other province and territory in Canada operates waste diversion programs, along with many US states and municipal entities. The products subject to diversion under Ontario's Circular Economy Law will be pre-dominantly the same supply "imported" into the other provinces, states, and territories in North America. As such, a workable solution in Ontario has the real benefit of being replicable at scale elsewhere in North America.

In fact, the Province of Ontario is effectively betting that, as a first mover in North America, that it develops the innovation with Ontario's scheme to then reproduce the know-how and industry elsewhere - a cottage industry with aspirations as a North American leader.

This was the plan with Ontario's Feed-in-Tariff renewable energy program introduced in 2008 where industry was to migrate to the province to produce "domestic content" renewable hardware in support of renewable energy. To a lesser degree, this was the plan for the Command Diversion Framework. Neither has worked as expected in spite of the substantial expenditures of capital. Arguably, the Ontario government did not step aside so as to allow sufficient certainty in the market for long-term investment.

More importantly, however, there is a clear mandate within the province to become the centralized source for waste diversion innovation and industry will be looking for scalable solutions, which can be mass produced across North America as the regulatory schemes mature ${ }^{35}$, backed by consistent standards and outcomes.

In short, the ability to replicate the Circular Economy Law elsewhere in North America is arguably a fundamental premise upon which it has been legislated in Ontario so its expansionist goals should come as no surprise.

\section{Resource Recovery "Wild West" in Need of Diversion Expertise / Solutions}

What is also clear from the impending Circular Economy Law are the needs of producers and related industry parties to find new environmentally-sound, yet market savvy strategies for their waste streams. As North America's first such program, the experience and expertise from the European Union and elsewhere will be highly valued in giving obligated parties the assurance that resource recovery and environmental compliance will be achieved using market-leading technologies.

The impending move to IPR has also created a period of volatility where innovation, experience, and business relationships are forming and reforming with uncertain results. As the Circular Economy Law will, to some degree, be replicated elsewhere in North America, the current Ontario model offers waste management participants with a rare opportunity to define the future.

\section{Jonathan Cocker *}

181 Bay Street, Suite 2100

Toronto, Ontario M5J 2T3 Canada

* email: jonathan.cocker@bakermckenzie.com

\section{ACKNOWLEDGEMENTS}

Special thanks to Peter Hargreave and his invaluable insights upon which this publication depended.

\section{REFERENCES}

Ontario Ministry of the Environment and Climate Change (2016) Strategy for a Waste-Free Ontario: Building the Circular Economy, (Queen's Printer for Ontario, 2016).

Ontario Ministry of the Environment and Climate Change (2016). Climate Change Action Plan 2016-2020, (Ontario Ministry of the Environment and Climate Change, 2016) accessed online: <http:// www.applications.ene.gov.on.ca/ccap/products/CCAP_ENGLISH. pdf>

Environmental Registry. Government of Ontario (2016). Draft Tire Regulation Under the Resource Recover and Circular Economy Act, 2016. http://www.ebr.gov.on.ca/ERS-WEB-External/displaynoticecontent.do?noticeld=MTMzODM2\&statusId=MjAzNTY1\&language $=$ en

U. Valiente (2016). A Practical Pathway to Producer Responsibility for Paper Products and Packaging in Ontario, December 6th, 2016, Corporate Policy Group LLP
1 Defined under the Resource Recovery and Circular Economy Act, 2016, 2016 SO 2016, c. 12 , Sch. 1 as "an economy in which participants strive: a) to minimize the use of raw materials; b) to maximize the useful life of materials and other resources through resource recovery; and c) to minimize waste generated at the end of life of products and packaging.

${ }^{2}$ SO 2016 c. 12

${ }^{3}$ Ontario Ministry of the Environment and Climate Change, Strategy for a Waste-Free Ontario: Building the Circular Economy, (Queen's Printer for Ontario, 2016) at p. 4 ["Strategy for a Waste-Free Ontario"].

${ }^{4}$ Ibid.

${ }^{5}$ Ontario Ministry of the Environment and Climate Change, Climate Change Action Plan 2016-2020, (Ontario Ministry of the Environment and Climate Change, 2016) accessed online: <http://www.applications.ene.gov.on.ca/ ccap/products/CCAP_ENGLISH.pdf>.

${ }^{6} 2002$, SO 2002, c. 6.

${ }^{7}$ The notion of a "producer" has been supplanted under s. 59 of the RRCEA with "brand holder", defined as a person who owns or licences a brand or who otherwise has rights to market a product under a brand.

${ }^{8}$ Strategy for a Waste-Free Ontario, supra at p. 4.

${ }^{9}$ Notably, IFO Ontario Tire Stewardship had the highest diversion rates for reasons which are only partially attributable to its relatively manageable and specialized set of waste diversion participants.

${ }^{10}$ SO 2016, c 12, Sch. 2.

${ }^{11}$ European Commission, Closing the loop - An EU action plan for the Circular Economy, (EUR-Lex: European Commission, Brussels, 2.12.2015)

${ }^{12}$ Defined under RRCEA as "material used in addition to primary packaging to facilitate consumer's handling, or transportation of one or more products, such as boxes and bags.

${ }^{13}$ Defined under the RRCEA as "material used in addition to primary packaging to facilitate the handling or transportation or one or more products by persons other than consumers, such as pallets, bail wrap and boxes, but does not include shipping containers designed for transporting things by road, ship, rail or air.

14 Under s.61(3) of RRCEA, a person who imports, wholesales, leases or retails product or is otherwise involved in the regulated product's distribution

${ }^{15}$ It could be argued that WDO also omitted any policy development work, but their central position and obfuscated mandate crowded out the MOECC from much policy initiative.

${ }^{16}$ Strategy for a Waste-Free Ontario, supra at 14-35.

${ }^{17} \mathrm{Ibid}$, at 14. 
${ }^{18} \mathrm{Ibid}$, at 17.

${ }^{19}$ Many of these concerns are highlighted in Usman Valiente's A Practical Pathway to Producer Responsibility for Paper Products and Packaging in Ontario, December 6th, 2016, Corporate Policy Group LLP.

${ }^{20}$ Recycling and Composting of Municipal Waste, O Reg 101/94.

${ }^{21}$ Waste Audits and Waste Reduction Work Plans, O Reg 102/94.

22 Industrial, Commercial and Institutional Source Separation Programs, 0

Reg 103/94

${ }^{23}$ Packaging Audits and Packaging Reduction Work Plans, O Reg 104/94.

${ }^{24}$ Draft Strategy for a Waste-Free Ontario, supra at 22.

${ }^{25} \mathrm{Ibid}$, at 22.

${ }^{26}$ Registrations Under Part II.2 of the Act - End-of-Life Vehicles, O Reg 85/16.

${ }^{27}$ Strategy for a Waste-Free Ontario, supra at. 24

${ }^{28}$ Climate Change Mitigation and Low-carbon Economy Act, SO 2016, c. 7.

${ }^{29}$ Strategy for a Waste-Free Ontario, supra at 26.

${ }^{30} \mathrm{Ibid}$, at 27

${ }^{31} \mathrm{Ibid}$, at 23

${ }^{32} \mathrm{Ibid}$, at 32

${ }^{33}$ Resource Recover Policy Branch, Ministry of the Environment and Climate Change, Draft Tire Regulation under the Resource Recovery and Circular Economy Act, 2016 (Public Consultation) (Ontario Ministry of the Environment an Climate Change, December 2017).

${ }^{34}$ RSC 1985, c C-34.

${ }^{35}$ While it might be easy to be pessimistic in viewing the near term commitment to environmental initiatives at the federal level in the United States, waste diversion continues to develop at the state and local levels. 